\title{
Case Report: Meningitis Streptococcus suis Presented with spondylodiscitis in Bali
}

\author{
I Made Oka Adnyana ${ }^{1 *}$, Ni Made Susilawathi ${ }^{1}$, Anak Agung Ayu Suryapraba Indradewi ${ }^{1}$, Faldi Yaputra ${ }^{1}$, Made Widhi Asih $^{2}$, \\ Ni Nyoman Sri Budayanti ${ }^{3}$, Sri Maliawan ${ }^{4}$ \\ ${ }^{1}$ Department of Neurology, Faculty of Medicine, Udayana University, Sanglah General Hospital, Bali, Indonesia; ${ }^{2}$ Department \\ of Radiology, Faculty of Medicine, Udayana University, Sanglah General Hospital, Bali, Indonesia; ${ }^{3}$ Department of Clinical \\ Microbiology, Faculty of Medicine, Udayana University, Sanglah General Hospital, Bali, Indonesia; ${ }^{4}$ Department of Neurosurgery, \\ Faculty of Medicine, Udayana University, Sanglah General Hospital, Bali, Indonesia
}

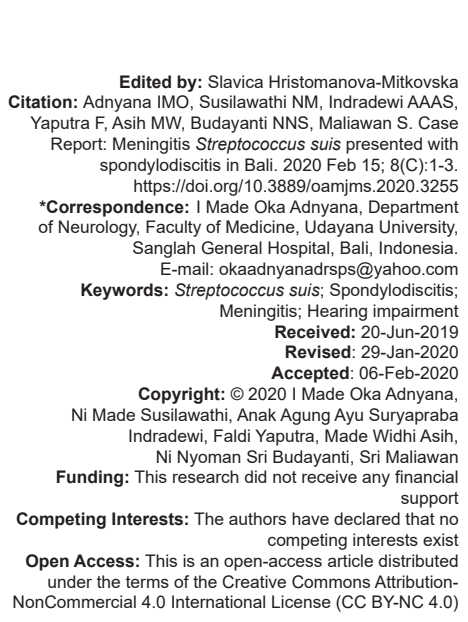

Background

Streptococcus suis is a Gram-positive microorganism, transmitted by pigs to human by direct contact with pigs. The most common clinical manifestation caused by this pathogen is meningitis followed by hearing impairment [1]. Other clinical presentations are sepsis, enteritis, arthritis, endocarditis, uveitis, and endophthalmitis [2],[3].

Since the first case of human infection of S. suis was reported in Denmark, in 1969 [1],[2],[3], many cases have been reported including in Indonesia. Bali is one of the provinces in Indonesia that the citizens are highly contacted with pigs or pork (https://bps. go.id/linkTableDinamis/view/id/1026). S. suis infection in human has been reported in Asia region; Japan 7 cases, Thailand 118 cases, Vietnam 293 cases, and China 332 cases [1]. Most of those cases presented with meningitis, spondylodiscitis caused by $S$. suis is rarely reported. We presented a case of $S$. suis infection with meningitis, spondylodiscitis, and hearing impairment.

\section{Case Report}

A 60-year-old man was admitted to the emergency room with a decrease of consciousness started gradually in the past $3 \mathrm{~h}$. The family reported that the patient was agitated and spoke incoherently. He had fever, headache, nausea, and vomiting in the past 3 days. Others medical histories are non-specific, except he had consumed pork 4 days before admission.

In admission, the vital sign was stable, blood pressure 140/80 $\mathrm{mmHg}$, heart rate $70 \mathrm{bpm}$, respiration rate $20 / \mathrm{min}$, and body temperature $36.2^{\circ} \mathrm{C}$. Clinical neurology examination revealed Glasgow Coma Scale $E_{2} V_{4} M_{5}$, neck stiffness, without any cranial nerve involvement, and other focal neurologic deficits. Routine laboratory test showed white blood cell count $10.63 \times 10^{3} / \mu \mathrm{L}$, neutrophil count $90.84 \%$, platelet $99.6 \times 10^{3} / \mu \mathrm{L}$, C-reactive protein level of $110.94 \mathrm{mg} / \mathrm{L}$, and random blood glucose level $163 \mathrm{mg} / \mathrm{dL}$. Serologic test for hepatitis $\mathrm{C}$, human immunodeficiency virus, and NS1 antigen for dengue was negative. In addition, 
cerebrospinal fluid (CSF) analysis showed pleocytosis $\left(766 / \mathrm{mm}^{3}\right)$ with polymorphonuclear $50 \%$, increased protein level $(692.7 \mathrm{mg} / \mathrm{dL})$, and low CSF glucose (4 mg/dL) with CSF:blood glucose ratio 0.02 . Head computed tomography scan with contrast was done, revealed a leptomeningeal enhancement and cerebral edema, suggesting a meningoencephalitis (Figure 1).

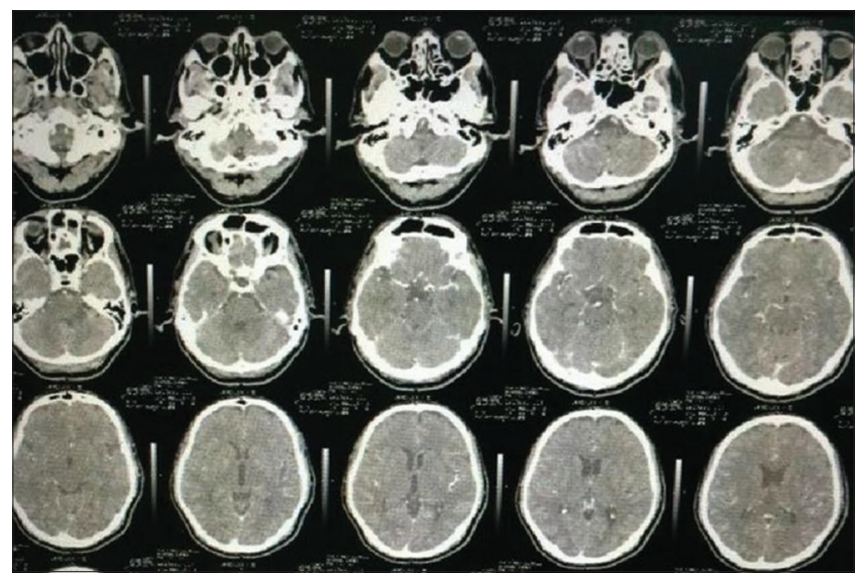

Figure 1: Axial head computed tomography scan with contrast at admission indicated meningitis

The patient was treated as an acute bacterial meningoencephalitis with intravenous antibiotic, steroid, and other supportive and symptomatic medications. One day after admission, he started to regain consciousness and complained of hearing impairment. We evaluated a bilateral sensorineural hearing impairment, consulted to the ENT department, and treated according to ENT protocol. After 4 days, the CSF culture revealed an isolated $S$. suis serotype II. He was diagnosed as bacterial meningoencephalitis caused by $S$. suis serotype II infection with bilateral sensorineural hearing impairment. In 2 weeks of treatment, the evaluation of CSF analysis was performed and it has improved compared to the previous CSF analysis result. The patient clinical condition also improved significantly and he was discharged with only hearing impairment remaining.

After 2 days of home care, he came back to the hospital complaining low back pain and hypesthesia on both legs. He started to feel this pain after the $1^{\text {st }}$ time spinal tapping and get worse for 1 day before the second admission. He had difficulties when walking and had to be carried.

Vital signs ware stable, and numeric pain rating scale for the low back pain was 7-8. The lower extremities examination could not be done yet due to the pain. No other neurological deficits were found. Laboratory tests were ordered, complete blood count and CSF were normal. Lumbosacral magnetic resonance imaging revealed lumbar spondylosis, spondylodiscitis at $L_{5}-S_{1}$ corpus vertebra level, a central bulging disc herniation at $\mathrm{L}_{4}-\mathrm{L}_{5}$, and disc protrusion to the central and right foramina at the level of $L_{5}-S_{1}$ corpus vertebra (Figure 2).

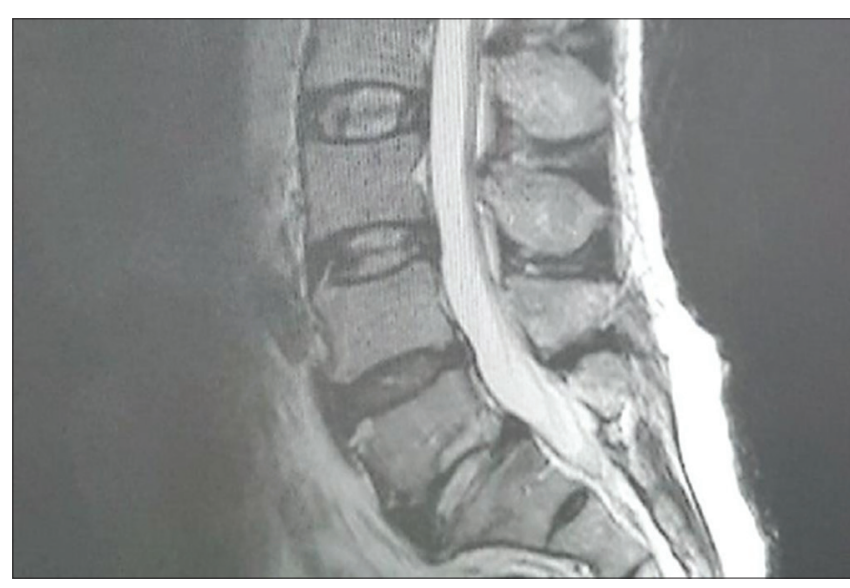

Figure 2: Lumbosacral magnetic resonance imaging indicates a spondylodiscitis at $L_{5}-S_{1}$ corpus vertebra level

He was treated as low back pain caused by spondylodiscitis caused by $S$. suis serotype II infection. Treatment was as follows: IV acetaminophen $1 \mathrm{~g}$ every $8 \mathrm{~h}$, IV ketorolac $30 \mathrm{mg}$ if pain scale more than 3 , IV ceftriaxone $2 \mathrm{~g}$ every $12 \mathrm{~h}$, IV ranitidine $50 \mathrm{mg}$ every $12 \mathrm{~h}$, and diazepam $2 \mathrm{mg}$ every night orally. The patient was consulted to neurosurgery and orthopedic department and no surgery was needed, conservative treatment was suggested. In 2 weeks of hospitalization, the symptom of low back pain was improved; he was discharged and scheduled for outpatient clinic visit in 1 week.

\section{Discussion}

Streptococcus infection, especially $S$. suis serotype II, needs a full concern, especially in preventing its emerging. Bali is one of the tourism destinations in Indonesia, with many traditional foods that consist of pork. Anyone that contacted pigs or pork material has increased the risk to be infected, such as pigs farmers, butchers, and veterinary practitioner [1]. The first human infection of $S$. suis was reported in 1968 in Denmark [2], [3], [4], [5], [6]. Many cases were followed, approximately 700-900 cases worldwide [2], [3]. In Southeast Asian countries, many cases were reported in China, Hong Kong, Japan, Korea, Thailand, and Vietnam [3]. A study in Hong Kong evaluated the etiology of bacterial meningitis in 65 adult patients for 10 -year period. He found that $S$. suis was the third most frequent cause. Infective endocarditis and septicemia may occur as frequent as meningitis [7]. In 2005, 206 cases were reported in China with 38 deaths [8].

The first case of $S$. suis infection had been reported in Korea with meningitis, septicemia, and spondylodiscitis. The patient came to the hospital with headaches, fever, chill, and hearing impairment. They confirmed $S$. suis infection from CSF evaluation and culture. The patient was given ceftriaxone for 14 days, 
but he developed back pain. The antibiotic substituted with ampicillin plus sulbactam, then the back pain resolved gradually. After 28 days of antibiotic therapy, the patient was discharged. The low back pain resolved completely after 1 month after discharge [2].

We reported the first case of $S$. suis serotype II infection in Indonesia who had a history of pork consumption 4 days before admission. He developed classic symptoms of acute bacterial meningitis with a headache, fever, neck stiffness, and altered mental status. The patient was treated with ceftriaxone for 14 days and discharged with the improvement of symptoms. He developed low back pain and hypesthesia on both legs on the $2^{\text {nd }}$ day of discharge. $\mathrm{He}$ readmitted to the hospital and received another course of ceftriaxone for 14 days. The symptoms were improved and he was discharged after 14 days. He was a previously healthy man and had no predisposing factors, such as malignancy, asplenia, diabetes mellitus, and alcoholism.

The most common manifestation of $S$. suis infection is meningitis followed by sepsis. Our patient manifested the less common complication of S. suis serotype II infection which was spondylodiscitis in the late course of the disease. He responded well with antibiotic and did not require any surgery. Like another microorganism that causes bacterial meningitis, $S$. suis is susceptible to penicillin, ceftriaxone, and vancomycin [2].

\section{Conclusion}

Meningitis suis is a systemic infection which can occur in any organ. This disease transmitted by pork product. The best prevention for this infection is avoiding direct contact and consumption of raw pork product. Spondylodiscitis is a rare complication of meningitis $S$. suis infection, the clinicians should aware of any low back pain in $S$. suis infection.

\section{References}

1. Zalas-Wiecek $\mathrm{P}$, Michalska A, Grabczewska E, Olczak A Pawlowska M, Gospodarek E. Human meningitis caused by Streptococcus suis. J Med Microbiol. 2013;62(3):483-5. https:// doi.org/10.1099/jmm.0.046599-0

PMid:23222864

2. Choi SM, Cho BH, Choi KH, Nam TS, Kim JT, Park MS, et al. Meningitis caused by Streptococcus suis: Case report and review of the literature. J Clin Neurol. 2012;8(1):79-82. https:// doi.org/10.3988/jcn.2012.8.1.79

PMid:22523518

3. Sena Esteves S, Carvalho de Almeida J, Abrunhosa J, Almeida E Sousa C, Arshad Q. Pig's ear: Streptococcus suis meningitis and its associated inner ear implications. IDCases. 2017;10:55-7. https://doi.org/10.1016/j.idcr.2017.08.015 PMid:28932685

4. Badung DK. Profil Kesehatan Kabupaten Badung 2017. Badung: Dinas Kesehatan Kabupaten Badung; 2018. https:// doi.org/10.23887/team.vol2.2017.224

5. Tandio D, Manuaba A. Safety procedure for biosafety and controlling a communicable disease: Streptococcus suis. Bali Med J. 2016;5(2):74-7. https://doi.org/10.15562/bmj.v5i2.220

6. Goyette-Desjardins G, Auger JP, Xu J, Segura M, Gottschalk M. Streptococcus suis, an important pig pathogen and emerging zoonotic agent-an update on the worldwide distribution based on serotyping and sequence typing. Emerg Microbes Infect. 2014;3(6):e45. https://doi.org/10.1038/emi.2014.45 PMid:26038745

7. Hui AC, Ng KC, Tong PY, Mok V, Chow KM, Wu A, et al. Bacteria meningitis in Hong Kong: 10-years' experience. Clin Neurol Neurosurg. 2005;107(5):366-70. https://doi.org/10.1016/j. clineuro.2004.10.006 PMid:16023529

8. Poggenborg R, Gaïni S, Kjaeldgaard P, Christensen JJ Streptococcus suis: Meningitis, spondylodiscitis and bacteraemia with a serotype 14 strain. Scand J Infect Dis. 2008;40(4):346-9. https://doi.org/10.1080/00365540701716825

PMid:18365920 